\title{
Seroprevalence of bovine brucellosis in agro pastoral areas of Jijjiga zone of Somali National Regional State, Eastern Ethiopia
}

\author{
Hailu Degefu ${ }^{1}$, Mohamed Mohamud ${ }^{2}$, Mussie Hailemelekot ${ }^{3}$ and Moti Yohannes ${ }^{1}$ \\ ${ }^{1}$ Jimma University, College of Agriculture and Veterinary Medicine. P.O.Box, 307, Jimma \\ ${ }^{2}$ Somali Regional State Livestock, Crop and Rural Development Bureau, P.O. Box, 206, Jijjiga \\ ${ }^{3}$ Bahir-Dar University, College of Agricultural and Environmental Sciences, P.O. Box, 79, Bahir \\ Dar
}

\begin{abstract}
A cross-sectional study was carried out from October 2008- March 2009 to determine the sero-prevalence of bovine brucellosis in four districts of Jijjiga Zone, eastern Ethiopia. Purposive sampling technique was employed to select the four districts and nine peasant associations (PAs). A total of 435 blood samples were collected from cattle of 6 or more months of age with no history of previous vaccination against brucellosis. All serum samples were initially screened by Rose-BengalPlate Test (RBPT) and those positive reactors to RBPT $(n=8)$ were further tested by complement fixation test (CFT) for confirmation. Out of the 8 RBPT positive sera 6 were found to be positive to CFT. Accordingly, the overall seroprevalence of bovine brucellosis in Jijjiga Zone was $1.38 \%$ (6/435). The seroprevalence of bovine brucellosis in the four districts namely Awbare, Harshi, Kebribayah and Fafan districtes were $0.78 \%, 2.91 \%, 2.06 \%$ and $0 \%$, respectively. Statistically there is no significant deference among the four districts $\left(\mathrm{X}^{2}=3.37 \mathrm{df}=3, \mathrm{P}=0.268\right)$. The study also revealed absence of significant statistical variation in the seroprevalence of brucellosis in different age and sex groups of the study animals $(\mathrm{P}>0.05)$. Result of this study showed that the seroprevalence of bovine brucellosis in the study area is low. However, it is highly likely that the disease spreads in unaffected animals and herds given the extensive production system prevailing in the area which may allow contact of animals during grazing and at watering points. The public in general and high risk group in particular should be made aware of the zoonotic importance of bovine brucellosis.
\end{abstract}

Keywords: Agropastoral, Bovine, Brucellosis, Ethiopia, Jijjiga, Seroprevalence 


\section{Introduction}

Brucellosis occurs worldwide in domestic animals such as cattle, sheep, goats, camels and pigs and creates a serious economic problem for both the intensive and extensive livestock production systems in the tropics (Schwabe, 1984; Seifert, 1996). It also causes considerable economic losses in livestock production due to abortion, infertility and reduction in milk production. In addition, the zoonotic nature of the disease has a serious impact on public health (GarinBastuji et al., 1998). Generally, the susceptibility of cattle to Brucella abortus infection is influenced by age, sex, management and reproductive status of the individual animal (Radostitis et al., 2000).

In Ethiopia, so far higher seroprevalence reports are 39\% in western Ethiopia (Meyer, 1980), 22\% in a dairy farm in northeastern Ethiopia (Tariku Sintaro, 1994), $11 \%-15 \%$ in dairy farms and ranches in southwestern Ethiopia (Tekleye Bekele et al., 2000), 8.2\% in Arsi area (Bayleyegne Molla, 1989) in central part of the country, 8.1\% in dairy farms in and around Addis Ababa (Yilkal Asfaw et al., 1998) and 7.7\% in Tigray region (Haileselassie Mekonn et al., 2010). Relatively low individual animal seroprevalence in intensive farms were recorded in different part of the country. Tadele Tolosa (2004) reported $0.77 \%$ in southwestern Ethiopia, Taddesse Yayeh (2003) observed a prevalence of $0.14 \%$ in north Gondar Zone and Kassahun Asmar et al (2007) documented 2.46\% in Sidama Zone of southern Ethiopia. Furthermore, a recent study conducted in pastoral and agropastoral areas of East Shoa Zones of Oromia Regional State by Hunduma and Regassa (2009) reported the prevalence of bovine brucellosis to be $15.2 \%$ for pastoral and $4.1 \%$ for agro-pastoral areas. Similar other studies on livestock brucellosis were done in pastoral and agropastoral areas of East Africa. Omer et al. (2000) reported 8.2\% sero-prevalence in Eritrea and El-Ansary et al. (2001) reported 5\% in Sudan. So far there is no published data on bovine brucellosis for agropastoral areas of Somalia Regional State. Therefore, the objective of this paper is to determine the seroprevalence of bovine brucellosis and to identify the risk factors associated with the seroprevalence in Jijjiga Zone of Somale Region of Ethiopia.

\section{Materials and Methods}

\section{Study Area}

The study was conducted in four districts (Kebribeyah, Awbare, Gursum and Harshin) of Jijjiga Zone of Somali National Regional State. Jijjiga Zone 
is situated in Eastern part of Ethiopia about 630km East of Addis Ababa with human population of 430,634 . The altitude of the zone ranges from 500 to 1650 meter above sea level and it is located between $9^{\circ} 20^{\prime}$ North latitude and $45^{\circ} 56^{\prime}$ East longitude. The climate of Jijiga Zone is semi-arid type which is characterized by high temperature. The mean annual rainfall in the area ranges from 600 to $700 \mathrm{~mm}$. Agro-pastoralism is the dominant production system in Jijjiga Zone.

\section{Study Animals}

The study animals were indigenous cattle breeds kept under extensive management system in the area. All cattle in the study area with the age of 6 months or above were considered as the study animals.

\section{Study design, sampling method and sample size}

The study design was a cross-sectional study carried out in indigenous cattle breed using serological tests where Rose Bengal Plate Test (RBPT) was used as screening test and Complement Fixation Test (CFT) was used for confirmation. The study was undertaken from October 2008 to March 2009.

The sampling method used was purposive sampling method. First the four study districts were selected purposively from Jijjiga Zone of Somalia Regional State (first stage). Then the nine peasant associations (PAs) within the selected districts were selected purposively, on the basis of prior information on the problem, farmers' cooperation, logistics, and accessibility. The name of PA's from where the samples were taken were Tahogilo and Harshika from Kebribeyah District; Gobare, Shibirbichara and Laru from Awbare District; Alidala and Dehawar from Harshin District and Fafan from Gursum District. The sample size for each district was determined by the formula recommended by Thrusfield, (1995) as indicated below:

\section{$\mathrm{N}=1.96^{2} \times \mathrm{PQ} / \mathrm{D}^{2}$}

Where $\mathbf{N}$ is required sample size, $\mathbf{P}$ is expected prevalence based on previous preliminary surveys, $\mathbf{Q}$ is $1-\mathbf{P}$ and $\mathbf{D}$ is the level of precision (5\%). Since there was no previous study carried out on bovine brucellosis in the study area, a 50\% expected prevalence as used in the formula.

Accordingly, the total number of animals to be bled from each district was 384, which makes a total sample size of 1536 for the four districts. However, 
due to the unwillingness of livestock owners to let their animals bled we only managed to collect 435 blood samples: 97 (79 female and 18 male) from Kebribeyah District, 130 (96 female and 34 male) from Awbare District, 103 (88 female and 15 male) from Harshin District and 105 (76 female and 29 male) from Guirsum District.

\section{Blood Sample Collection}

Approximately $10 \mathrm{ml}$ of blood sample was collected from the jugular vein of each animal using plain vacationer tube and needles. Each sample was labeled by using codes describing the specific animal. Serum was separated from clotted blood by centrifuging. Separated serum was collected in a screw caped sterilized plastic vial and stored at $-20^{\circ} \mathrm{C}$ until tested.

\section{Serological Tests}

\section{Rose Bengal Plate Test (RBPT)}

Rose Bengal Plate Test was performed according to the standard procedure described by Alton et al (1975). The test was carried out at Jijjiga Regional Veterinary Diagnostic and Research Center (JRVDR). The antigen of RBPT, consisted of a suspension of Brucella abortus, was obtained from Institut Purquier 326 (Rue de la Galera, 34097 MONTPELLIER CEDEX 5, France). The results were read by examining the degree of agglutination in good light source and when deemed necessary using magnifying glass. Any visible agglutination was considered positive (OIE, 2004).

\section{Complement Fixation Test (CFT)}

Sera, which reacted positive to RBPT, were retested by Complement Fixation Test (CFT) (OIE, 2004) as confirmatory test to eliminate any cross reaction at the National Veterinary Institute (NVI), Debre Zeit. Antigen, control sera and complement were obtained from the BgVV, Berlin, Germany. The reading of results for the CFT was carried out as follows: When there was complete fixation (no haemolysis) with clear water supernatant, result was recorded as ++++ , nearly complete fixation ( $75 \%$ clearing) as +++ , partial haemolysis $(50 \%)$ as ++ and some fixation (25\% clearing) as + . Complete lack of fixation (complete haemolysis) was recorded as 0 . For positive reactions final titrations was registered (OIE, 2004).Interpretation: Serum with strong reaction, more than $75 \%$ fixation of complement (3+) at a dilution of $1: 5$ and at least with $50 \%$ fixation of complement $(2 \%)$ at a dilution of $1: 10$ and at dilution of 1:20 were classified as positive (OIE, 2004). 
Data Analysis

Data was stored in the Microsoft Excel spread sheet program and analyzed using STATA 8.0 (2003). The seroprevalence was calculated by dividing the number of CFT positive animals by the total number of animals tested. Chisquare test was utilized to measure the association between the seroprevalence with categorical variables (districts). In addition, Fisher's exact test was utilized when the outcome variable was below five in number as a substitute for Chi square test in comparing two factors among each other.

\section{Results}

Out of the total 435 serum samples, $8(1.84 \%)$ were positive to RBPT. The 8 RBPT positive sera were retested with CFT and $6(1.38 \%)$ were found to be positive. The overall seroprevalence of bovine brucellosis in Jijjiga Zone is thus $1.38 \%$ (6/453). The individual animal seroprevalence of bovine brucellosis in the four district of Jijjiga Zone ranged from $0 \%$ to $2.91 \%$ (Table 1). There was no statistically significant variation in individual animal seroprevalence of brucellosis among the four districts ( $>0.05$ ). Comparatively, the highest seroprevalence of brucellosis was recorded in Harshi District (2.91\%) and no seropositive animal was found in Gursum District.

Table1. Sero-prevalence of bovine brucellosis in four districts of Jijjiga Zone, Eastern Ethiopia

\begin{tabular}{lcccc}
\hline District & No animals tested & RBPT positive & CFT positive & 95\% CI for CFT \\
\hline Awbare & 130 & $3(2.31 \%)$ & $1(0.78 \%)$ & $0.74-0.82$ \\
Gursum & 105 & $0(\%)$ & $0(\%)$ & - \\
Harshin & 103 & $3(2.06 \%)$ & $3(2.91 \%)$ & $2.78-3.06$ \\
Kabribayah & 97 & $2(2.06 \%)$ & $2(2.06 \%)$ & $1.98-2.14$ \\
Total & 435 & $8(1.84 \%)$ & $6(1.38 \%)$ & $1.35-1.41$ \\
\hline
\end{tabular}

$\mathrm{X}^{2}=3.97 . \mathrm{DF}=3, \mathrm{P}=0.268$

The seroprevalence of brucellosis in female animals was $1.77 \%$ while there was no seropositive male animal. However, the overall and district level differences in seroprevalence between the two sexes were not statistically significant $(\mathrm{p}>0.05)$. 
Table 2. Sero-prevalence of Bovine Brucellosis in relation to sex in the four districts of Jijjiga zone, Eastern Ethiopia

\begin{tabular}{lccccc}
\hline District & Sex & $\begin{array}{c}\text { Number of } \\
\text { animals tested }\end{array}$ & $\begin{array}{c}\text { CFT } \\
\text { positive }\end{array}$ & $\begin{array}{c}\text { Prevalence } \\
\text { (\%) }\end{array}$ & $\begin{array}{c}\text { Fisher's exact } \\
\text { test P-value }\end{array}$ \\
\hline Awbare & Female & 96 & 1 & 1.04 & 0.738 \\
& Male & 34 & 0 & 0 & - \\
Gursum & Female & 76 & 0 & 0 & 0.620 \\
& Male & 29 & 0 & 0 & 0.662 \\
Harshin & Female & 88 & 3 & 3.41 & 0.346 \\
& Male & 15 & 0 & 0 & 2.53 \\
Kabribayah & Female & 79 & 2 & 0 & 0 \\
& Male & 18 & 0 & 1.77 & 0 \\
\hline
\end{tabular}

The sero-prevalence of brucellosis in the young and adult age groups is presented in (Table 3). All the seropositive cattle were above 2 years of age (adult) $(1.5 \%)$ although there was not statistically significant difference between the two age groups $(\mathrm{P}>0.05)$.

Table3. Seroprevalence of bovine brucellosis in two age groups in four districts of Jijjiga Zone

\begin{tabular}{lcccc}
\hline Age & $\begin{array}{c}\text { No. animals } \\
\text { tested }\end{array}$ & $\begin{array}{c}\text { CFT } \\
\text { positive }\end{array}$ & $\begin{array}{c}\text { Prevalence } \\
\text { (\%) }\end{array}$ & $\begin{array}{c}\text { Fisher's exact } \\
\text { test } \\
\text { P-value }\end{array}$ \\
\hline 6 month to 2 years & 35 & 0 & 0 & 0.608 \\
>2 years & 400 & 6 & 1.5 & \\
Total & 435 & 6 & 1.38 & \\
\hline
\end{tabular}

\section{Discussion}

The present study revealed that the overall seroprevalence of bovine brucellosis was $1.38 \%$ in the four district of Jijjiga Zone. This low sero-prevalence is comparable with other reports in different parts of Ethiopia; $4.9 \%$ in Arsi by Abay (1999), 4.2\% in Ghibe and Gobe by Tekleye Bekele et al. (1989), 2.15\% in central highlands of Ethiopia by Assegid Bogale (1987), 1.92\% in Sidama Zone by Kassahun Asmare et al (2007), 0.61\% in Jimma by Tadele Tolosa(2004), no positive reactors in Selale and Addis Ababa by Kelay Belihu (2002)., 1.49\% in Tigray Region by Gebretsadik Berhe (2005), 1.113\% from cattle slaughtered at Addis Ababa and Sululata Abattoirs by Mulugeta Tefera (2006) and 2.3\% in 
Adaa Liban Dairy Cooperatives by Abrham Abebe et al. (2008). Slightly higher seroprevalence was recorded in agropastoral areas of East Shoa Zone (4.1\%) by Hunduma and Regassa (2009) and in Bahir Dar milk shed (4.63\%) by Mussie Hailemelekot et al (2007).

In addition to this, seroprevalence as high as $38.7 \%$ was reported in cattle owned by the Institute of Agriculture Research (IAR) by Muktar Reshid (1993), 22\% in Chafa State Dairy Farm by Tariku Sintaro (1994), 19.5\% in Abernosa Cattle Breeding Ranch by Taye Yirgu (1991), $16.65 \%$ in and around Bahirdar by Abeje Shiferaw (1994) and 15.8\% in Sidamo by Endrias Zewdu (1989). Similarly, moderate seroprevalence rates were reported by Bayleyegn Molla (1989) in Arsi (8.2\%), by Gebreyesus Mekonnen (2001) (unpublished). in North Western Amhara on local indigenous zebu (8.2 \%) and by Yilkal Asfaw et al (1998) in urban and peri-urban areas around Addis Ababa (8.11\%). The different in seroprevalence of bovine brucellosis reported from different parts of Ethiopia might be due to difference in management and grazing system, and husbandry conditions.

In the current study, there was no positive reactor among male animals, although the difference in seroprevalence between the two sexes was not statistically significant. This finding is in agreement with the work done by Tesfaye Abebe (2003) in Tigray region, Taddess Yayeh (2003) in North Gondar Zone, and Tadale Tolosa (2004) in Jimma Zone who reported only female positive reactors. On the other hand, Yilkal Asfaw et al. (1998) reported a $0.11 \%$ seroprevalence among male animals while Mussie Hailemelekot et al (2007) reported $2.11 \%$ seroprevalence in extensive management system. Although no controlled study has been conducted on the relative susceptibility of female and male cattle to brucellosis, based on reactor rates it is probable that bulls are more resistant than sexually mature heifers and cows, however, are less resistant than sexually immature heifers (Nicoletti, 1980). It is important to note that serological data may underestimate Brucella abortus infection in males as infected bulls tested might be generally non-reactors or only had low antibody levels (Crawford et al., 1990).

In this study, higher seroprevalence of bovine brucellosis was observed in older age category ( $>2$ years of age) $(1.5 \%)$ than younger age category (6 months to 2years) $(0 \%)$, although the difference was statistically insignificant. This observation is in agreement with that of Yilkal Asfaw et al. (1998) where seroprevalence of bovine brucellosis in older cattle (4\%) was higher than in younger ones (1.9\%). Tariku Sintaro (1994) had also found higher proportion 
of old cattle being affected, but the difference among age groups was not statistically significant. Kassahun Asmare et al (2007) reported that the majority (97.87\%) of sero-reactors were detected in the animals older than 2 years in both the extensive and intensive management systems. Tadele Tolosa (2004) and Mussie Hailemelekot et al. (2007) too reported significant variation among age groups in extensive production systems with higher seroprevalence rates in older animals. Similar result was also reported by Abraham Abebe et al (2008) in east Showa. It is evident that susceptibility of cattle to Brucella abortus infection is influenced by age of individual animals. Young and sexually immature animals tend to be more resistant to infection and frequently clear infection, although latent infections do occur (Radostits et al., 2000).

In conclusion, the result of this study showed that the seroprevalence of bovine brucellosis in Jijjiga Zone is found to be low. However, it is highly likely that the disease spreads to the unaffected animals and herds given the extensive production system prevailing in the area which may allow contact of animals during grazing and at watering points. Thus, there is a need to design and implement control measures aiming at preventing further spread of the disease in the Region through the use of better management practices. In addition, the public in general and high risk group in particular should be made aware of the zoonotic potential of brucellosis.

\section{References}

Abebe, A., Kassa, T., Degefu, T., \& Hassen, E., 2008. Investigation on seroprevalence of bovine brucellosis and related major reproductive health disorders in Ada'a Liben Dairy Cooperative. Eth. Vet. J., 12(2), 19-31.

Abebe, T., 2003. Sero-epidemiological study of cattle and small ruminant brucellosis in selected sites of Tigray, Northern Ethiopia. DVM Thesis, Addis Ababa University, Faculty of Veterinary Medicine, Debre Zeit.

Alton, G. G., Jones, M. L. and Pietz, D. E., 1975. Laboratory techniques in brucellosis. Food and Agriculture Organization and World Health organization of the United Nations. Rome.

Asfaw, Y., Molla, B., Zessin, H.K., and Tegene, A., 1998. The epidemiology of bovine brucellosis in intra and periurban dairy production systems in and around Addis Ababa. Bull. Anim. Hlth. Prod. Afr., 46, 217-224 
Asmare, K., Shiu Prassad, Asfaw, Y., Gelaye, E., Ayele, G., \& Zeleke, A., 2007. Seroprevalence of brucellosis in cattle \& high risk animal health professionals in Sidama Zone, Southern Ethiopia. Eth. Vet. J ., 11(2), 59-68.

Bekele, A, 1999. Bovine brucellosis sero-epidemiological study in selected farms and ranches in Southeastern Ethiopia. DVM Thesis, Faculty of Veterinary Medicine, Addis Ababa University, Debre Zeit, Ethiopia.

Bekele, A., Molla, B., Asfaw, Y., and Yirgu, L., 2000. Bovine brucellosis sero epidemiological study in selected farms and ranches in southern Ethiopia. Bull. Anim. Hlth. Prod. Afr., 48, 13-17.

Bekele, T., Kassali, O.B., Mugurewa, M. Sholtens, R.G., Tamirat, Y., 1989. The prevalence of brucellosis in indigenous cattle in Central Ethiopia. Bull. Anim. Hlth. Prod. Afr., 37, 97-98.

Belihu, K., 2002. Analysis of dairy cattle breeding practices in selected areas of Ethiopia. Humboldt University of Berlin, Berlin, Germany, PhD Thesis.

Bogale, A., 1987. Seroprevalence study of bovine brucellosis in different management of central Ethiopia. DVM Thesis, FVM, AAU, Debre Zeit, Ethiopia.

Crawford, R. P., Huber, J. D. and Adams, B. S., 1990. Epidemiology and surveillance. In: Nielsen, K. and Duncan, J. R. (eds.), Animal Brucellosis, Florida, CRC Press Inc., pp. 131-148.

El-Ansary, E. H., Mohammed, B., Hamad, A., A. R. and Karom, A. G., 2001. Brucellosis among animals and human contacts in Eastern Sudan. Saudi Med. J., 22: 577579.

Garin-Bastuji, B., Blasco, J.M., Grayon, M., and Verger, J.M., 1998. Brucella melitensis infection in sheep: present and future. Vet. Res., 29, 255-274.

Berhe, G., 2005.Seroepidemiological study of bovine brucellosis in Tigray Region, Northern Ethiopia. MSc Thesis, FVM, AAU, Debre Zeit, Ethiopia.

Hailemelekot, M., Kassa, T., \& Assfaw, Y., 2007. Seroprevalence study of bovine brucellosis in Bahir Dar milk shed, Northwestern Amhara Region. Eth. Vet. J. 11(1), 49-65.

Haileselassie, M., Shewit, K. and Moses, K., 2010. Serological survey of bovine brucellosis in barka and arado breeds (Bos indicus) of Western Tigray, Ethiopia. Prev. Vet. Med., 94 (1-2), 28-35. 
Hunduma, D. and Regassa, C. 2009. Seroprevalence study of bovine brucellosis in pastoral and agro-pastoral areas of East Showa Zone, Oromia Regional State, Ethiopia. Am-Euras. J. Agric. \& Environ. Sci., 6 (5): 508-512.

Mayer, C. E. 1980. Report on Veterinary Activity. Institute of Agricultural Research, Ethiopia

Molla, B., 1989. Sero-epidemiological survey of bovine brucellosis in Arsi Region. DVM Thesis, FVM, AAU, Debre Zeit, Ethiopia.

Tefera, M, 2006. Study on bovine brucellosis in cattle slaughtered at Addis Ababa and Sululta Abattoirs with focus on occupational hazard. Msc Thesis, Faculty of Veterinary Medicine, Addis Ababa University, Debre Zeit, Ethiopia.

Nicoletti, P., 1980. The epidemiology of bovine brucellosis. Adv. Vet. Sci. Comp. Med.,

OIE, 2004. Manual of Diagnostic Tests and Vaccines for Terrestrial Animals. 5th ed., Office International des Epizootics, Paris, pp 409-438.

Omer, K., G. Holstand, E. Skjerve, Z. Woldehiwet and G. MacMillian., 2000. Prevalence of antibodies to brucella species in cattle, sheep, goats, horses and camels in the State of Eritrea, influence of husbandry system. Epidemiol. Infect., 125: 447-453

Radostits, E.D., Gay, C.C. and Inchcliff, K.W., 2000. Veterinary Medicine, Textbook of the Diseases of Cattle, Sheep, Pigs, Goats and Horses. 9th ed., New York, W.B. Saunders Company Ltd, pp 867-882.

Reshid, M., 1993. Reproductive wastage in cattle due to bovine brucellosis. In: Proceedings of the Fourth National Livestock Improvement Conference, Institute of Agricultural Research, Addis Ababa, 13-15 November 1993, pp 270-272.

Schwabe, C.W., 1984. Human health costs of animal diseases. In: Veterinary Medicine and Human Health, 3rd ed., Williams and Wilkins, pp 33-35

Seifert, H. S., 1996. Tropical Animal Health. 2nded., Dordrecht, Kluwer Academic Publishers Group, pp 356-368.

Shiferaw, A., 1994. Seroepidemiological study of bovine brucellosis in and around Bahir Dar. DVM Thesis, FVM, AAU, Debre Zeit, Ethiopia.

Sintaru, T., 1994. The impact of brucellosis on productivity in improved dairy herd of Chaffa State Farm, Ethiopia. MSc Thesis, Frei Universitaet Berlin, Berlin, Germany. 
Stata Corp. 2003. Stata Statistical Software: Release 8. College Station, TX: Stata Corp LP.

Thrusfield, M. 1995. Veterinary Epidemiology 2ed edition.UK: Back well scientific Ltd. Pp $182-198$.

Tolosa. T., 2004. Seroprevalence of bovine brucellosis and its public health significance in selected sites of Jimma Zone, Western Ethiopia. MSc Thesis, FVM, AAU, Debre Zeit, Ethiopia.

Yayeh. T., 2003. A survey of bovine brucellosis in selected areas of North Gondar Zone. DVM Thesis, Addis Ababa University, Faculty of Veterinary Medicine, Debre Zeit.

Yirgu, T., 1991. Sero-prevalence of bovine brucellosis at Abernosa.. Addis Ababa University, Faculty of Veterinary Medicine, Debre Zeit, DVM Thesis.

Zewdu, E., 1989. Sero-prevalence study of bovine brucellosis in selected sites of Sidamo Region. DVM Thesis, FVM, AAU, Debre Zeit, Ethiopia. 